This manuscript was peer-reviewed and accepted for publication in its current form in Social Psychological and Personality Science. This version is not the copy of record and may not exactly replicate the authoritative published document.

\title{
Absolute Certainty and Political Ideology: A Systematic Test of Curvilinearity
}

\author{
Thomas H. Costello \\ Shauna M. Bowes \\ Emory University, Department of Psychology
}

\begin{abstract}
Author Note
This research was conducted according to the guidelines of the Declaration of Helsinki and all studies were approved by the Institutional Review Board of Emory University. The authors have no conflicts of interest to disclose. Correspondence should be addressed to Thomas H. Costello, 36 Eagle Row, Department of Psychology, Emory University, Atlanta, GA, 30322. Email: thcostello1@gmail.com.
\end{abstract}




\begin{abstract}
The present investigation examined curvilinear relations between left-right political ideology, on the one hand, and absolute certainty and dogmatism, on the other, across six online samples $(\mathrm{N}=2889)$. Ideological extremists were more likely than others to be absolutely certain: about 1 in 3 extremists reported being absolutely (i.e., 100\%) certain of the correctness of their political beliefs, whereas about 1 in 15 non-extremists reported being absolutely certain. Although absolute political certainty was relatively symmetrical across the political left and right, conservatives tended to report greater domain-general dogmatism than liberals. Extremism effects for domain-general dogmatism were also present, however, and ideological asymmetries in dogmatism appeared to be driven by social, rather than economic, ideology. Taken together, these findings underscore the complexity of relations between absolute certainty, dogmatism, and ideology, ultimately challenging the sufficiency of contemporary psychological accounts of ideological a/symmetries to describe our complex political reality.
\end{abstract}




\section{Absolute Certainty and Political Ideology: A Systematic Test of Curvilinearity}

Behavioral scientists have repeatedly observed that certain strains of political ideology disproportionately attract individuals who are highly, unjustifiably certain that their beliefs are correct (e.g., Altemeyer, 1996; Rokeach, 1960). Specifically, considerable evidence supports the possibility that right-wing political attitudes are linked to unjustified certainty (i.e., dogmatism; Jost, 2017). Accordingly, many authors have embraced the rigidity-of-the-right framework, which posits that conservative ideology dovetails with dogmatism (and other rigidity-related variables) because it promises certainty in a way that left-wing ideology rarely does (e.g., Jost et al., 2003). By contrast, however, an expanding pool of recent studies suggests that individuals who espouse radical or extremist political beliefs also tend to be dogmatic. Toner et al. (2013), for instance, found that ideological extremism is tied to the degree to which people view their political attitudes as superior to those of others, a finding conceptually replicated by Rollwage et al. (2018) and directly replicated by Harris and Van Bavel (2020). Similarly, van Prooijen and Krouwel (2017) found that political extremists are higher than moderates in both domain-general and politics-specific dogmatic intolerance (i.e., rejecting and/or derogating the beliefs of others). These findings are consistent with the ideological extremism framework, which posits that extremist ideologies appeal to highly certain thinkers who conceptualize the world in unambiguous, black-and-white terms (van Prooijen \& Krouwel, 2017; Zmigrod et al., 2019). The rigidity-of-the-right and ideological extremism frameworks significantly diverge in their theoretical implications. The former implies that dogmatism is an essential difference between conservatives and liberals, while the latter implies that the extremity of one's political beliefs is of greater psychological relevance than their content. Nevertheless, the extent to which right-wing vs. extremist philosophies are psychologically compatible with dogmatism remains an 
open question, and the two frameworks may be reconcilable. Extensive evidence suggests that ideological asymmetries and symmetries in dogmatism may be found, depending on how dogmatism and political ideology are operationalized and which types of samples are used, among other boundary conditions ${ }^{1}$ (Harris \& Van Bavel, 2020; Zmigrod, 2020; see Costello et al., 2021a, for a review). Further, the primary dependent variable in many of the above-discussed findings (i.e., Harris \& Van Bavel, 2020; Toner et al., 2013; van Prooijen \& Krouwel, 2017) might be termed "inter-ideological certainty," the notion that one's beliefs are more correct than opposing beliefs, which may differ conceptually from dogmatism (i.e., unjustified belief certainty). One might report with a high degree of certainty, for instance, that their beliefs about the earth's shape are more correct than someone who believes the earth is flat- this can hardly be considered evidence of dogmatism or absolutism (Baron \& Jost, 2019).

Here, we leverage the concept of absolute belief certainty (Lewis, 1929) to arbitrate between the rigidity-of-the-right and ideological extremism hypotheses. Absolute certainty describes beliefs that are subjectively and objectively immune to doubt (Klein, 1992). From a Bayesian perspective, endorsing absolute certainty (i.e., a prior of 1) implies that one will not update their beliefs even when shown evidence to the contrary (see Tripp, 2018). Hence, absolute certainty epistemically diverges from all other gradations and "flavors" of certainty, closedmindedness, and dogmatism, which leave room for belief updating (Kahan, 2013). Moreover, the limits of deductive reasoning preclude absolute certainty (Johnson-Laird, 1999), such that

\footnotetext{
${ }^{1}$ Prior tests of the rigidity-of-the-right have tended to subsume a host of loosely interrelated variables under the broad heading of rigidity, broadly spanning cognitive inflexibility, rigid cognitive styles, motivational rigidity, and dogmatic certitude (Costello et al., 2021). Here, we focus only on dogmatism, which may not bear meaningful relations with these other "flavors" of rigidity.
} 
absolute certainty seems to be necessarily unjustifiable and irrational ${ }^{2}$. Accordingly, absolute certainty might be considered the farthermost extremity of dogmatism (i.e., unjustified belief certainty; Altemeyer, 1996). Although it remains an open question whether this epistemic divergence between absolute belief certainty, on the one hand, and other kinds of belief certainty and dogmatism, on the other, reflects meaningful psychological variance, absolute certainty may have substantive psycho-political implications. Sir Karl Popper (1945) went so far as to argue that absolute certainty is the foundational component of totalitarianism: if one is sure that their political philosophy will lead to the best possible future for humankind, all manner of terrible acts become justifiable in service of the greater good.

In many respects, absolute certainty is the opposite pole of intellectual humility, a cognitive-personological construct that comprises acceptance of the limits of one's beliefs, modesty about one's beliefs, and tolerance of disconfirmatory information (e.g., Leary et al., 2017; Tanesini, 2016). Intellectual humility has seen a great deal of research attention in political psychology, not least because it seems to buffer against political polarization, political bias, belief superiority, and authoritarianism, and is correlated with cognitive flexibility and objectivism (Bowes et al., 2020; Davis et al., 2016; Zmigrod et al., 2019). Many of these relations have proven invariant across the political left and right (e.g., Bowes et al., 2021), raising the question of whether the rigidity-of-the-right or ideological extremism models wield explanatory power for intellectual humility and absolute certainty.

\footnotetext{
${ }^{2}$ Whereas overconfidence (i.e., $95 \%$ certainty about a prospect that is only $25 \%$ certain) should be assessed in relation to the veracity of a given belief (e.g., certainty about anthropogenic climate change vs. certainty about the earth's roundness), absolute certainty reflects a category error. Hence, absolute certainty is equally irrational for all beliefs and is, therefore, an unbiased measuring stick with which to compare individuals with beliefs of differing truth values (e.g., liberals and conservatives; see Baron \& Jost, 2019).
} 
Hence, examining the ideological correlates of absolute certainty and other varieties of dogmatism may offer clear, interpretable evidence concerning left-right (a)symmetries and ideological extremism effects in unjustified certainty. In the present studies, we collapse six community samples (total $N=2,889$ ) to test the explanatory power of rigidity-of-the-right and ideological extremism models for absolute political certainty and domain-general dogmatism. In so doing, we account for conceptual and methodological issues that have impeded informative comparisons of the two frameworks on five fronts. First, we measure absolute certainty, which has yet to be examined in relation to political ideology and arguably reflects the extreme pole of dogmatism. Second, to probe relations between unjustified certainty and political ideology more comprehensively, we administer two domain-general dogmatism questionnaires that differ in their conceptualizations of dogmatism. Third, to facilitate optimized tests of curvilinearity, as well as to maximize statistical power, we use latent variable modeling to clarify and test the dimensional structure of these dogmatism measures. Fourth, due to the growing number of Americans who identify as socialists or are otherwise identify as extremely left wing, we distinguish steadfast liberals from more extreme leftists in sensitivity analyses, thereby accounting for obscured curvilinearity due to a potential restriction-of-range at the extreme left (Tetlock, 1989). Fifth, given the accumulating evidence that social and economic conservatism bear differing and potentially opposing relations with a host of psychological characteristics (Costello \& Lilienfeld, 2020), we examine global, social, and economic ideology separately.

\section{Method}

\section{Participants and Procedure}

Participants were recruited via Amazon's Mechanical Turk (MTurk) across six rounds of data collection. These data were not collected expressly for the purposes of the present study 
and, as such, participants completed a battery of psychological and attitudinal measures that varied across rounds of data collection. Nevertheless, the same measures of political ideology, certainty, and absolute certainty were administered across Samples 1 thru 4, so we combined these four samples to yield a single large sample (Set 1 ; total $N=1,940$ ). Similarly, the same measure of domain-general dogmatism (i.e., the DOG Scale) was administered in Samples 1, 2, 3 , and 6 (Set 2; total $N=1,933$ ) and an additional measure of domain-general dogmatism (i.e., the Dogmatism [D] Scale) was administered in Samples 1 and 5 (Set 3; total $N=998$ ). Sample size was therefore determined on the basis of available data. As is typical of online community samples (Levay et al., 2016), most of our participants were politically liberal and relatively moderate. Nevertheless, our large sample size allowed for a considerable degree of resolution at the ideological poles (e.g., 560 participants identified as either "very right-wing" or "extremely right-wing" and 1,070 identified as either "very left-wing" or "extremely left-wing").

Table 1. Overview of Data Collection and Demographics

\begin{tabular}{lcccc}
\hline & $\mathrm{N}$ & $\begin{array}{c}\text { Absolute Certainty } \\
(\text { Set 1) }\end{array}$ & $\begin{array}{c}\text { DOG Scale } \\
(\text { Set 2) }\end{array}$ & $\begin{array}{c}\text { D-Scale } \\
(\text { Set 3) }\end{array}$ \\
\hline Sample 1 & 508 & $\checkmark$ & & $\checkmark$ \\
Sample 2 & 498 & $\checkmark$ & $\checkmark$ & \\
Sample 3 & 466 & $\checkmark$ & $\checkmark$ & \\
Sample 4 & 477 & $\checkmark$ & & \\
Sample 5 & 490 & & $\checkmark$ & $\checkmark$ \\
Sample 6 & 479 & & $\checkmark$ & \\
\hline Total N & & 1949 & 1933 & 998 \\
Age (SD) & & $39.6(12.0)$ & $39.5(12.2)$ & $38.0(11.8)$ \\
\% Female & & 55.2 & 53.2 & 48.4 \\
\% White & 79.7 & 79.3 & 79.8 \\
\% Black & 11.2 & 12.0 & 9.7 \\
\% Asian & & 5.9 & 5.8 & 7.1 \\
\% Democrats & & 46.8 & 44.6 & 50.2 \\
\% Republicans & & 26.9 & 27.2 & 27.0 \\
\% Independent & & 10.9 & 17.1 & 3.8 \\
\% Libertarian & & 3.0 & 2.9 & 4.5 \\
\% Socialist & & 1.7 & 1.9 & 2.6 \\
\% Unaffiliated & & 6.1 & 5.8 & 10.9 \\
\hline
\end{tabular}




\section{Measures}

Political Ideology. In all samples, participants identified their political party affiliation as one of the following categories: Republican, Democratic, independent, Socialist, Green, Other, or None. Further, participants indicated the degree to which they symbolically identified as leftwing vs. right-wing generally, as well as in the economic and social domains, using a Likert-type scale with 7 response options $(1=$ extremely liberal/left-wing to $7=$ extremely conservative/right-wing). We also calculated a political ideology variable wherein all participants who self-identified as socialists had their symbolic identification responses recoded as "0" (i.e., further left than " 1 "), thereby distinguishing leftists from liberals for sensitivity analyses.

Absolute Certainty. To assess absolute certainty, we asked participants to respond to the following item: "How certain are you that your political beliefs are correct?". Participants were asked to respond on a 100-point scale ranging from $0 \%$ certainty to $100 \%$ certainty. Given that we were interested in absolute certainty, we calculated a binary variable ("0" = less than 100\%; $" 1 "=100 \%$ ) to distinguish high certainty from absolute certainty. Raw (i.e., continuous) scores were also retained and analyzed. Participants tended to report being highly certain of their political views $\left(\mathrm{M}_{\text {Certainty }}=75.1 \%, \mathrm{SD}=20.9 \%\right)$, with over half reporting greater than $80 \%$ certainty and $246(12 \%)$ reporting absolute certainty. Consequently, the certainty distribution was negatively skewed (skewness $=-1.05$, kurtosis $=1.01)$.

Dogmatism. To assess dogmatism, we administered the DOG Scale (Altemeyer, 1996; $\alpha=.92$ ), a 20 -item measure of ostensibly unjustified belief certainty regarding "big" or “important" issues. We used latent variable modeling to explore the DOG Scale's dimensional 
structure and calculate factor scores that best reflect a substantive core of dogmatism (i.e., EFA in $40 \%$ of the data followed by a CFA comparing plausible factor structures in the other $60 \%$; see Supplemental Files 1 and 2). Still, there is reason to suspect the DOG Scale demonstrates test bias for political ideology (i.e., scores may have differential validity across political groups; Conway et al., 2016). As such, we also used a modified measure designed to assess Rokeach's (1960) conceptualization of dogmatism (see Costello \& Lilienfeld, 2020; Costello et al., 2021). This measure was constructed by adopting or slightly altering the wording of 8 items of Rokeach's (1960) Dogmatism (D) Scale and adding 10 original items with good face validity for Rokeach's broad conceptualization of dogmatism as generalized authoritarianism. We again used latent variable modeling to determine the Dogmatism Scale's factor structure (see Supplemental Files 1 and 3). As evidence of construct validity, this modified D-Scale was highly related to, but not isomorphic with, the DOG Scale $(r=.49)$.

\section{Data Analytic Approach}

For all outcome variables, the linear and curvilinear effects of political ideology were examined using hierarchical multiple regression. For instance, for continuously scored political certainty standardized ideology scores were entered as a predictor of certainty in the first step of a regression analysis. In the second step, the squared value of the standardized scores was entered as an additional predictor and change in model fit across steps 1 and 2 was used to assess

curvilinearity. Specifically, the incremental influence of the quadratic term was assessed using $R^{2}$ and BIC. Following Raftery's (1995) recommendation, a decrease in BIC of 3 or greater was considered evidence of a better-fitting model. Further, we used BIC to derive Bayes Factors, an index of relative evidence for model comparisons (Wagenmakers, 2007). To probe relations between political ideology and absolute certainty, we followed a similar approach using binary 
logistic regression. In addition to BIC, McFadden's (1974) pseudo- $\mathrm{R}^{2}$ calculation was used to examine the incremental contribution of the curvilinear effect for each model.

Where curvilinearity was present (i.e., model fit improved), we sought to ascertain whether the relation between ideology and certainty followed the "u-shape" relation posited by the ideological extremism model using the two-lines test (i.e., interrupted regression; Simonsohn, 2018). The two-lines test estimates a regression line for low $\mathrm{x}$-values (in this case representing left-wing ideology) and high $\mathrm{x}$-values (right-wing ideology). This category split allows for a test of whether the two slopes (1) have opposing signs and (2) are statistically significant, based on a break point set using the Robin Hood algorithm. Finally, we directly compared extremely rightwing participants with extremely left-wing participants by means of $t$-tests. We investigated the robustness of these models via sensitivity analyses for age, gender, education, and cross-sample variation (see Supplemental File 1).

\section{Results}

\section{Certainty}

Republicans $(\mathrm{M}=78.86 \%[77.27,80.40])$ reported a greater degree of certainty than did Democrats $(\mathrm{M}=75.73 \%[74.30,77.05]), t(1439)=2.95, p=.003, d=0.16($ see Figure $\mathrm{S} 1)$. Independents $(68.06 \%[64.80,71.31]$ reported significantly lower certainty than Republicans $(t[737]=6.84, p<.001, d=0.52)$ and Democrats $(t[1134]=4.84, p<.001, d=0.35)$.

There was not a significant linear relation between political ideology and certainty $(\beta=$ $.00,95 \% \mathrm{CI}[-.05, .04])$. In contrast, the quadratic certainty term was large and significant $(\beta=$ $.45,95 \%$ CI $[.40, .49])$ and, accordingly, model fit was improved in Step 2, such that $\Delta R^{2}=.165$ (95\% CI $[.13, .20]), \Delta \mathrm{BIC}=-340, \mathrm{BF}>1000$ (see Table S1). Per the two-lines test, the slope of the line on the left $(z=-13.40, p<.001)$ and right $(z=15.03, p<.001)$ side of the breakpoint 
value $(x=4)$ were significant, with opposing signs, indicating that political extremism is roughly equivalently associated with increased certainty on both poles of the political spectrum (see Figure S2). Specifically, a one-unit increase in left-wing ideology was associated with an increase of $7.16 \%$ in certainty, while a one-unit increase in right-wing ideology was associated with an $8.61 \%$ increase in certainty. Still, certainty among members of the extreme right $(91.46 \%$ $[89.56,93.35])$ was significantly larger than certainty among members of the extreme left, with a small to medium effect size $(86.45 \%[84.52,88.35]), t(421)=3.13, p=.002, d=0.34$. We conducted a similar regression model after recoding the ideology variable to distinguish leftists from liberals. Doing so diminished model fit $(\triangle \mathrm{BIC}=80, \mathrm{BF}<.001)$, so we did not proceed with this more complex model. 


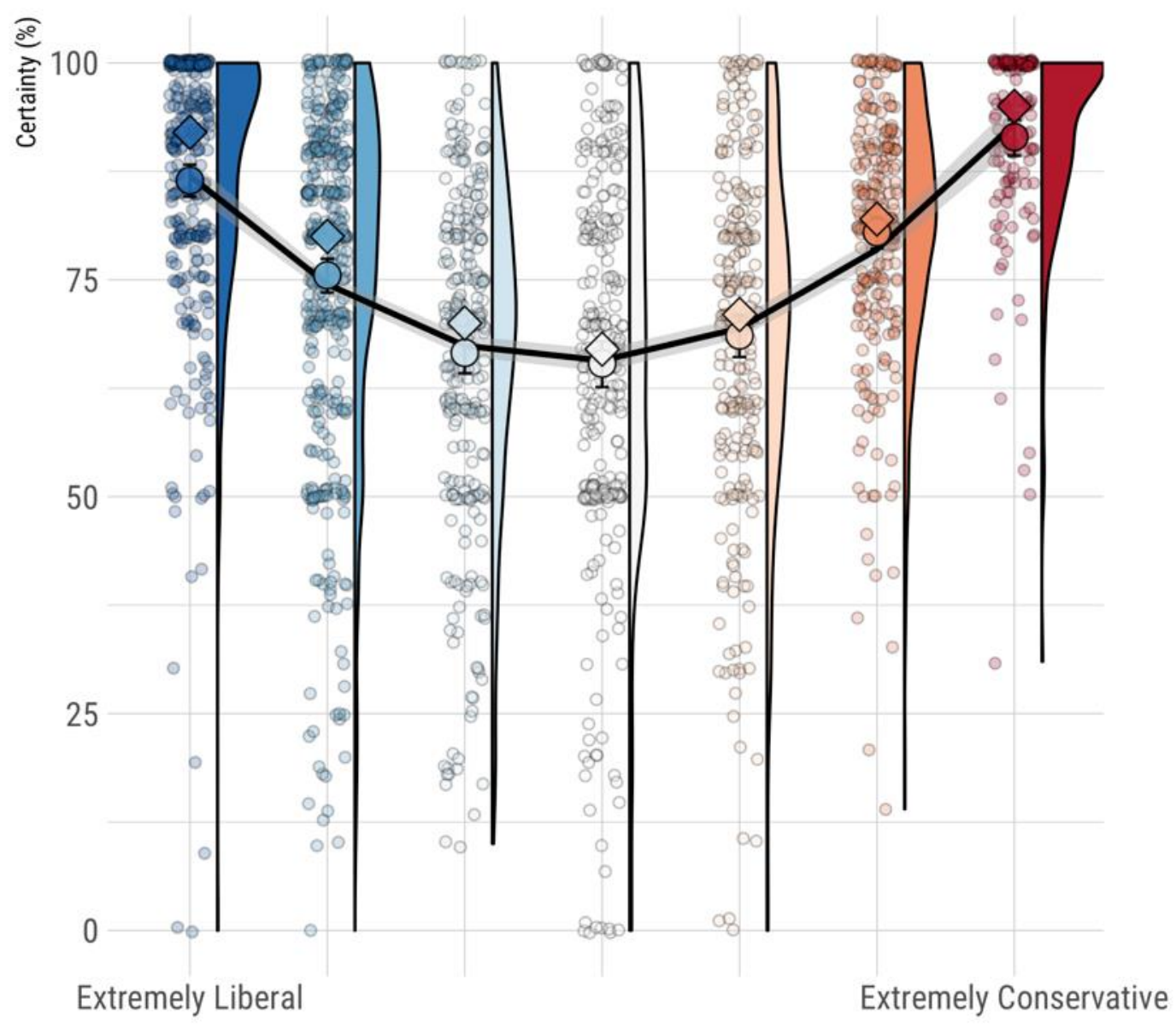

$N=1926$

Figure 1. Quadratic model for political certainty and political ideology. Circles denote mean certainty (with 95\% CIs) and diamonds denote median certainty at each level of the ideology variable.

\section{Social vs. Economic Ideology}

Neither economic nor social conservatism manifested a significant linear relation with certainty $(\beta s=-.02$ and $.02, p s=.309$ and .402 , respectively). When a quadratic term was added to both models, fit substantially improved (see Tables S3 and S4). For economic conservatism, the quadratic term was $\beta=.49(.44, .55), \Delta R^{2}=.177,95 \% \mathrm{CI}(.14, .21), \Delta \mathrm{BIC}=-275, \mathrm{BF}>$ 1000; for social conservatism, the quadratic term was $\beta=.48(.44, .55), \Delta R^{2}=.167,95 \% \mathrm{CI}$ 
$(.13, .20), \Delta \mathrm{BIC}=-256, \mathrm{BF}>1000$. The economic model was better fitting than the full social model, $\Delta \mathrm{BIC}=-25, \mathrm{BF}>1000, \Delta R^{2}=.010$, suggesting that extremism effects in economic ideology are more pronounced than those for social (see Figure S3). Supporting this possibility, the two-lines test suggested that a u-shaped relation was present in both the social and economic models (see Figures S4 and S5), but the slopes were more symmetrical for the economic model ( $b \mathrm{~s}=-8.69$ and 9.35, respectively) than the social model $(b \mathrm{~s}=-7.40$ and 9.66). This may be because individuals identifying as extremely economically left-wing expressed similar certainty $(86.68 \%[84.38,88.78])$ as individuals identifying as extremely economically right-wing $(88.67 \%[86.06,90.86]), t(378)=1.17, p=.244, d=0.12$, whereas individuals identifying as extremely socially left-wing expressed lower certainty $(83.97 \%[81.76,85.94])$ than those identifying as extremely socially right-wing $(91.19 \%[88.63,93.32]), t(420)=3.71, p<.001, d=$ 0.36 .

\section{Absolute Political Certainty}

Although a greater proportion of socialists (24.2\%) endorsed absolute certainty than did members of the Democratic (12.5\%) and Republican parties (14.6\%), absolutely certainty did not significantly differ across political party, as shown in Figure S6. Further, the linear effect of ideology did not account for a significant degree of variance in absolute certainty, $\chi^{2}=0.43, p=$ $.510, B=-.05, \mathrm{OR}=0.96(0.83,1.09)$, pseudo- $R^{2}=.014$ (see Table S5). When the quadratic term was added, however, the model accounted for a significant degree of variance $\chi^{2}=192.83$, $p<.001, B=1.02, \mathrm{OR}=2.77[2.39,3.23])$ and demonstrated substantially improved fit $\left(\Delta\right.$ pseudo- $\left.R^{2}=.179, \Delta \mathrm{BIC}=185, \mathrm{BF}>1000\right)$. The two-lines test was significant for both the left $(\mathrm{b}=-.14, \mathrm{z}=-.947, p<.001)$ and right $(\mathrm{b}=.06, \mathrm{z}=7.72, p<.001)$, providing evidence of a $\mathrm{U}$ shaped relation between absolute certainty and political ideology (see Figure S6). 
Absolute certainty was endorsed by 91 of the 290 (31.4\%) individuals who identified themselves as "extremely left-wing" and 54 of the 133 (40.6\%) individuals who identified themselves as "extremely right-wing". By contrast, only $6.8 \%$ of all other participants endorsed absolute certainty (see Figure 2). Extreme right participants were not significantly more likely to endorse absolute certainty than were extreme left participants, $t(421)=1.86, p=.064, d=0.19$. These results point to a substantial bilateral extremism effect for absolute certainty. Separating Democrats from far-left parties failed to improve model fit, $\Delta \mathrm{BIC}=1, \mathrm{BF}<.001, \Delta$ pseudo- $R^{2}=$ .00 , so we did not proceed with these more complex analyses.

\section{Social vs. Economic Ideology}

The linear effect of both economic conservatism $\left(\chi^{2}=2.42, p=.120, \mathrm{~B}=-.12\right.$, OR $=0.88$ $[0.76,1.03])$ and social conservatism $\left(\chi^{2}=0.06, p=.813, \mathrm{~B}=.02, \mathrm{OR}=1.02[0.87,1.87]\right)$ was not significant (see Table S7 and S8), whereas the addition of the quadratic terms accounted for additional variance in the case of both economic conservatism $\left(\chi^{2}=145.92, p<.001, \mathrm{~B}=1.00\right.$, $\mathrm{OR}=2.72[2.29,3.24], \Delta$ pseudo- $\left.R^{2}=.116, \Delta \mathrm{BIC}=-139, \mathrm{BF}>1000\right)$ and social conservatism $\left(\chi^{2}=148.14, p<.001, \mathrm{~B}=1.05, \mathrm{OR}=2.85[2.39,3.42], \Delta\right.$ pseudo- $R^{2}=.121, \Delta \mathrm{BIC}=-145, \mathrm{BF}>$ 1000). The two-lines test (see Figures S7 and S8) revealed identical slopes on the left and right for economic ideology $(\mathrm{b}=|.09|, p \mathrm{~s}=-8.43$ and $7.41, p \mathrm{~s}<.001)$ with a breakpoint at the neutral value of the ideology scale. For social ideology, however, the slope was greater for left-wing (b $=-.11, \mathrm{z}=-7.75, p<.001)$ than right-wing $(\mathrm{b}=.06, \mathrm{z}=6.83, p<.001)$, with a breakpoint at "slightly left-wing," rather than "neutral," such that the line of fit resembled a "fishhook" rather than "u-shape". 


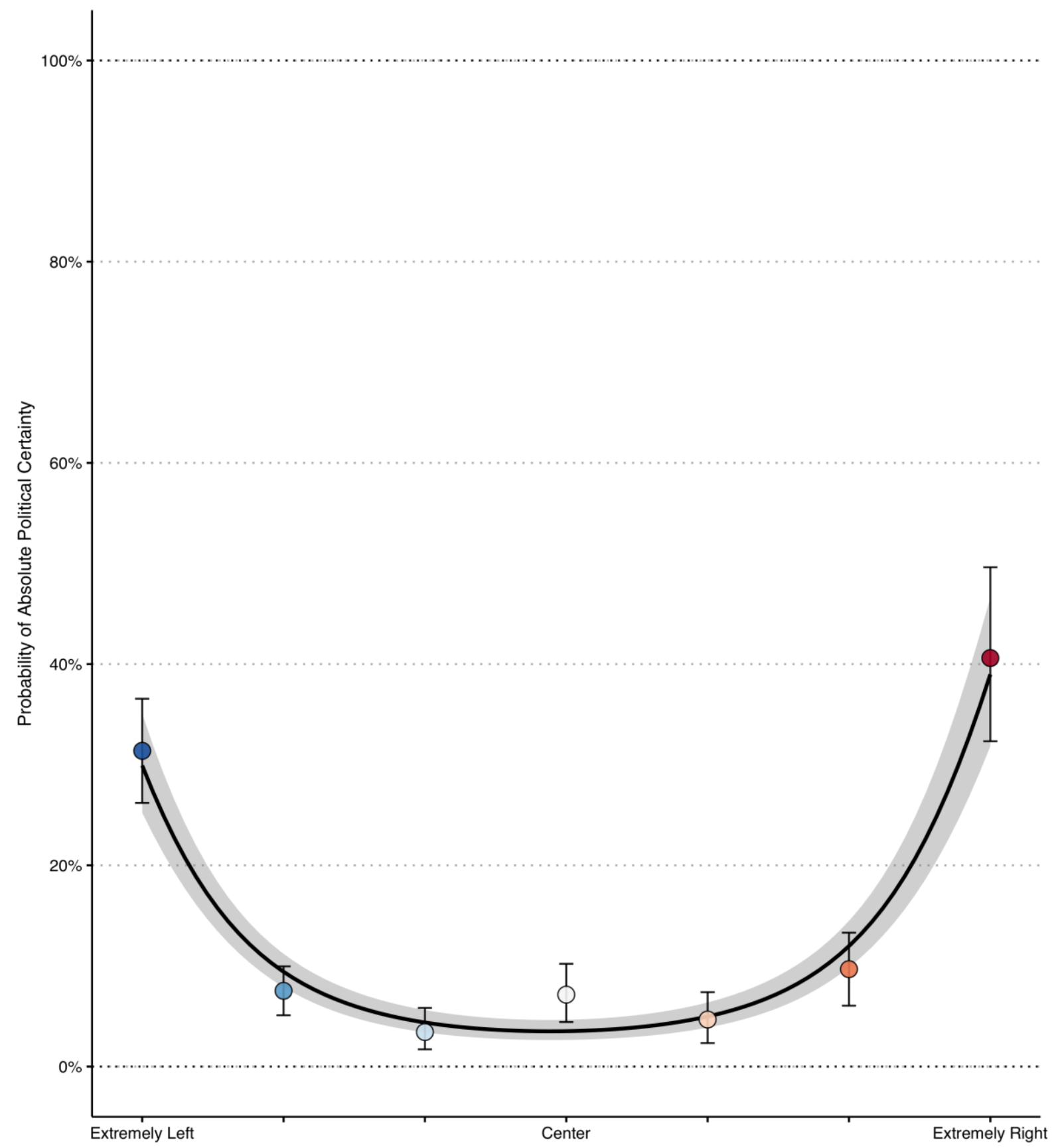

Figure 2. Likelihood of endorsing absolute (i.e., 100\%) certainty across political ideology in a logistic regression with curvilinear and linear terms.

\section{Dogmatism}

DOG Scale 
Republicans $(\mathrm{N}=520 ; \mathrm{M}=0.41[0.31,0.50])$ had positive mean DOG Scale scores, whereas Democrats $(\mathrm{N}=853 ; \mathrm{M}=-0.15[-0.20,-0.09])$ tended to score below the sample mean $(t=0.57, p<.001, d=0.57[0.46,0.68])$. Socialists $(\mathrm{N}=37 ; \mathrm{M}=-0.14[-0.48,0.19])$ were also statistically significantly less dogmatic than Republicans $(t=3.03, p=.003, d=0.26[0.09$, $0.42])$ and did not significantly differ from Democrats $(t=-0.02, p=.984, d<0.01[-0.13$, 0.13]). All other party-level results are presented in Figure S10.

Accordingly, there was a significant linear relation between the DOG Scale and political conservatism $(\beta=.30[.26, .34], p<.001)$. Still, the addition of a quadratic ideology term in Step 2 resulted in improved model fit, such that $\Delta R^{2}=.052$ (95\% CI $\left.[.03, .07]\right), \Delta \mathrm{BIC}=106, \mathrm{BF}>$ 1000, with the quadratic term $\beta=.24(.19, .28), p<.001$ (see Table S10). As illustrated in Figure 3 , the curvature pattern was less symmetrical than that for political certainty: DOG Scale scores for members of the extreme right $(1.12[0.91,1.32])$ were considerably larger than scores for the extreme left $(-0.08[-0.19,0.04]), t(396)=10.76, p<.001, d=1.08(0.87,1.29)$. Indeed, the twolines test was significant for the right $(\mathrm{b}=.30, z=13.57, p<.001)$ and the left $(\mathrm{b}=-.09, \mathrm{z}=-$ $2.36, p=.018$ ), but with a breakpoint at "slightly left-wing," rather than "neutral," providing evidence of both curvilinearity and asymmetry. When using our recoded symbolic ideology variable, the $\beta s$ for the linear and curvilinear relations were largely the same, and the added complexity modestly deteriorated model fit $(\triangle \mathrm{BIC}=5, \mathrm{BF}=.117)$. As such, evidence in favor of both the rigidity-of-the-right and ideological extremism models was present, but the rigidity-ofthe-right better accounted for the data. 


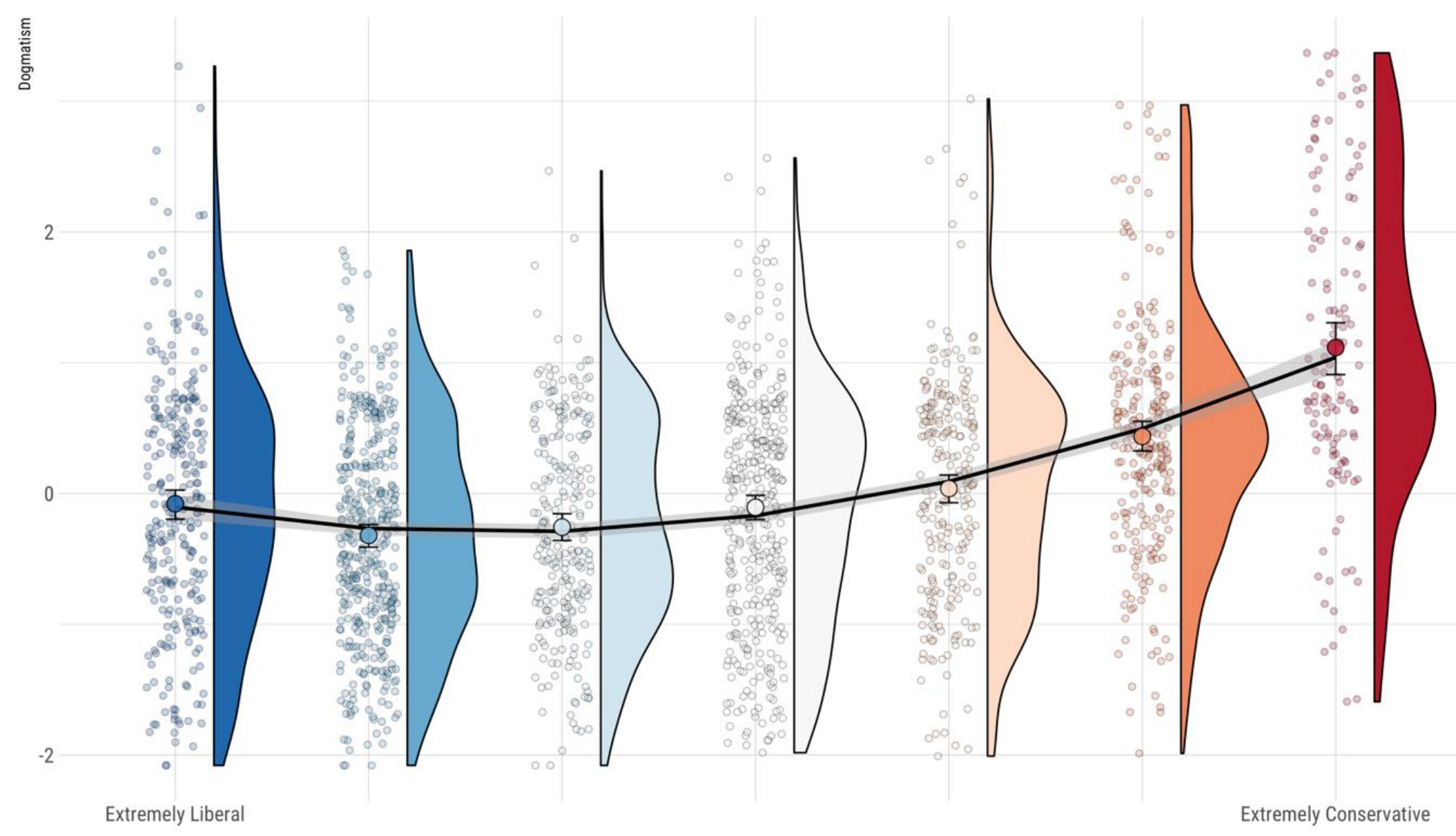

$N=1933$

Figure 3. Quadratic regression model for DOG Scale general factor scores and political ideology. Circles denote point estimates (with 95\% CIs). 
Social vs. Economic Ideology. There was a modest linear relation between economic conservatism and the DOG Scale, $\beta=.20(.15, .24), p<.001$, and a larger linear relation between social conservatism and the DOG Scale $\beta=.34(.30, .39), p<.001$. For economic conservatism, the curvilinear term was significant, $\beta=.27(.23, .32), p<.001, \Delta R^{2}=.074, \Delta \mathrm{BIC}=-155, \mathrm{BF}>$ 1000. Social conservatism demonstrated a similarly sized curvilinear relation, $\beta=.22(.17, .27)$, $p<.001, \Delta R^{2}=.044, \Delta \mathrm{BIC}=98, \mathrm{BF}>1000($ see Figure $\mathrm{S} 11)$. The full model for social conservatism was better fitting than that for economic conservatism, $\Delta \mathrm{BIC}=-156, \mathrm{BF}>1000$, and $\Delta R^{2}=.055$ (see Tables S11 and S12). Nevertheless, the line of fit was more symmetrical for economic conservatism, for which the two-lines test revealed a slope of -.11 $(\mathrm{z}=-.27, p=.007)$ for the left and a slope of $.24(z=10.5, p<.001)$ on the right, with a breakpoint at "slightly leftwing". For social conservatism, the slope was not significant on the left $(b=-.06, z=-1.81, p=$ $.070)$ and was significant on the right $(\mathrm{b}=.33, z=14.55, p<.001)$, with a breakpoint at "slightly left-wing". A more detailed analysis of this dynamic is presented in Supplemental File 1.

\section{Dogmatism Scale}

As with the DOG Scale, Republicans $(0.33$ [0.23, 0.43]) were more dogmatic than Democrats $(-0.14[-0.21,-0.07])$ on the D Scale $(t=7.49, p<.001, d=0.54[0.40,0.69])$ (see Table S12). Socialists (0.22 [-.14, 0.58]), however, were not significantly less dogmatic than Republicans $(t=0.616, p=.538, d=0.07[-0.16,0.30])$. A positive linear relation between the $\mathrm{D}$ Scale and political conservatism was present, $\beta=.26(.21, .31), p<.001$. The addition of the quadratic term in Step 2 improved model fit (see Table S13), suggesting the presence of a curvilinear effect, $\beta=.14(.09, .21), \Delta R^{2}=.020, \Delta \mathrm{BIC}=-15, \mathrm{BF}>1000$ (see Tables $\mathrm{S} 11$ and S12). Nevertheless, as illustrated in Figure 4, this curvilinearity was asymmetrical, such that while the two-lines test was significant for both the right $(b=.23, \mathrm{z}=8.31, p<.001)$ and the left 
( $\mathrm{b}=-.21, \mathrm{z}=2.63, p=.009$ ), the breakpoint was at "very left-wing" (i.e., " 2 " on our scale of 1 to 7) such that the line of fit resembled a fishhook (see Figure S12). Separating leftists from liberals and re-conducting the analyses suggested a greater degree of symmetry, $\Delta \mathrm{BIC}=-26, \mathrm{BF}=7.76$, and $\Delta R^{2}=.031$, with the two-lines test revealing slopes of $\mathrm{b}=-.21$ and .19 for the left and right, respectively, $p s<.002$, and a breakpoint of "somewhat left-wing" (see Figure S13). Social and economic conservatism were measured in only one of the two samples comprising Set 3 , so we do not report these analyses due to insufficient statistical power for detecting curvilinear effects. 

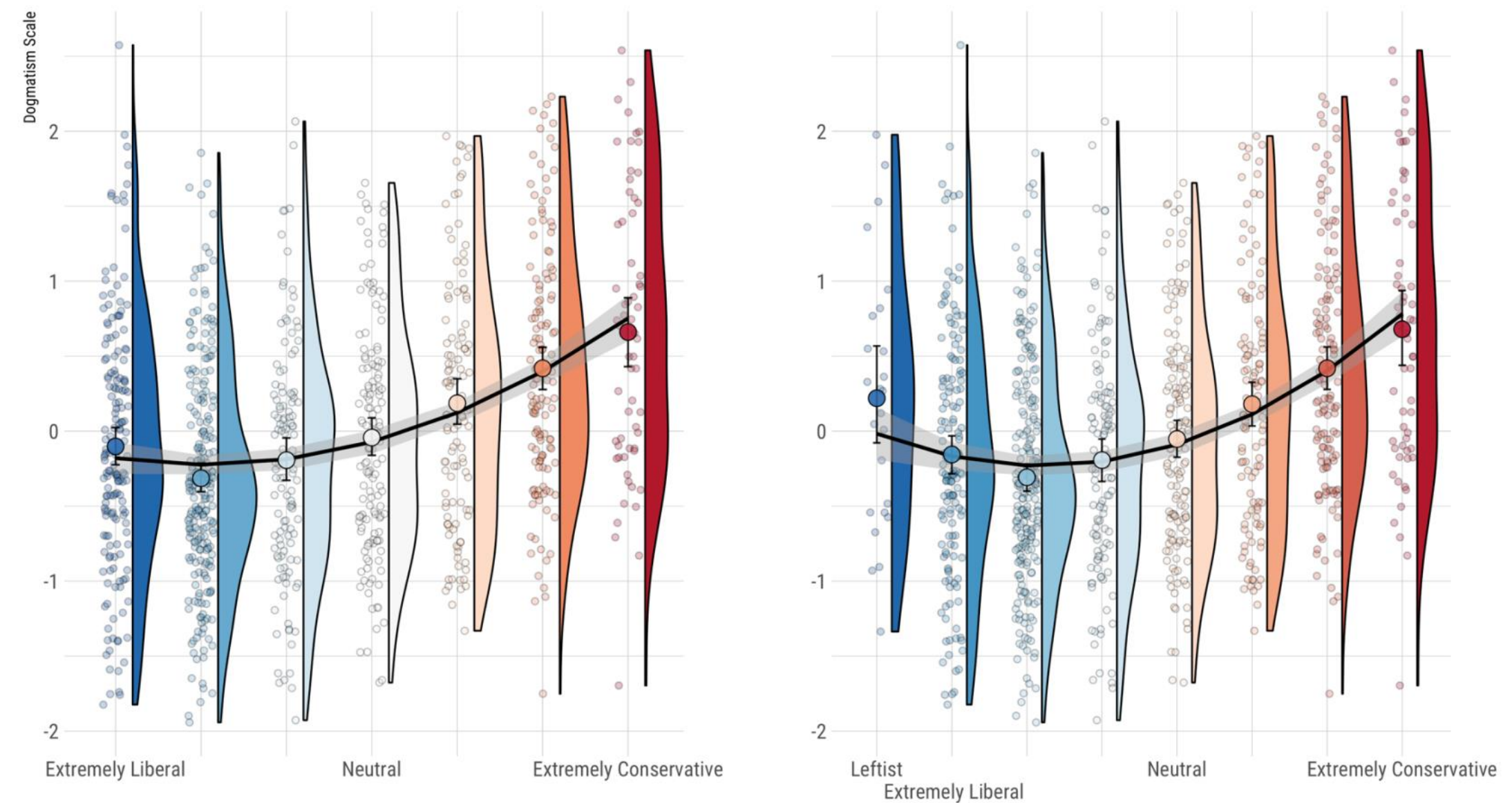

$N=998$

Figure 4. Quadratic regression model for general factor D Scale scores and political ideology. Circles denote point estimates at each response level (with 95\% CIs). The left-hand plot does not distinguish leftists from liberals, whereas the right-hand plot does distinguish leftists from liberals. 


\section{Discussion}

Individuals who identify themselves as "extremely left-wing" or "extremely right-wing" are roughly five times more likely than all others to be $100 \%$ certain that their political beliefs are correct. These results squarely accord with the "ideological extremism" model of political cognition, which holds that proponents of radical belief systems tend to be dogmatic, irrational, and cognitively inflexible (Zmigrod et al., 2019). Our data also point to a surprisingly precipitous ideological "cliff" of absolute certainty: whereas about 4 in 10 people who self-identified as "extremely left-wing" or "extremely left-wing" were $100 \%$ certain, only roughly 1 in 10 participants with only slightly less polarized views (i.e., identifying as "very left-wing" or "very right-wing") were $100 \%$ certain, which was about the same ratio as people who self-identified as politically neutral. If we take the logical step of assuming that the U.S.'s growing political polarization (e.g., Wilson et al., 2020) has been accompanied by growing absolute certainty, these findings may partially explain the partisan rancor, lack of intellectual humility, and governmental deadlock that have come to characterize U.S. politics (Kalmoe \& Mason, 2019).

Thus, the relation between political absolute certainty and ideological extremism appears to be straightforward. For non-political beliefs, however, our results were less clear-cut. Conservatives tended to be much higher on domain-general dogmatism than liberals, suggesting that conservatives are either psychologically disposed toward dogmatism (Altemeyer, 2002; Duckitt, 2009; Crowson, 2009) or are motivated to describe and understand themselves as dogmatic (see Costello et al., 2021). Still, (a) these left-right asymmetries appeared to be largely or entirely driven by variation in social conservatism (see Malka \& Soto, 2015) and (b) domaingeneral dogmatism increased at the extreme left. Hence, neither the rigidity-of-the-right nor the ideological extremism model can be said to offer a comprehensive account of our data. 
Indeed, our results point to substantial heterogeneity in dogmatism-ideology relations. A sizable fraction of individual extremists and conservatives numbered among the least dogmatic participants in our sample, while a sizable fraction of individual moderates and liberals numbered among the most dogmatic. Although this heterogeneity may merely be a product of imprecise measurement or attributable to the influence of environmental, rather than psychological, determinants of ideology (Kalmoe, 2020), these results again highlight the limited explanatory power of both models: overconfidence and dogmatism are exclusive neither to one side of the political spectrum nor to moderates.

Our results also provide preliminary evidence that the slope and symmetry of extremism effects differs across social and economic ideology. Namely, individuals with extreme left economic views were more dogmatic than those with extreme left social views, whereas individuals with extreme right economic views were less dogmatic than those with extreme right social views. Given that conservatives tended to be more dogmatic than liberals, the symmetrical U-shaped curve posited by the ideological extremism model was approximated in the economic domain. In contrast, in the social domain, the shape of the line of fit trends towards a fishhookshape, such that the right extreme is clearly more dogmatic than the left. These findings carry intriguing implications for literature suggesting that different components (e.g., social vs. economic) of a single belief system (e.g., conservatism) can satisfy competing or even opposing psychological needs, leading a highly psychologically heterogeneous group of individuals to proclaim their adherence to what is, nominally, the same ideology (Feldman, 2013; Federico \& Malka, 2021). Social conservatism and economic leftism may share structural and psychological features that are congenial to ideological extremism, perhaps because both social conservatives 
and economic leftists seek to impose top-down constraints on personal freedoms to safeguard collective societal wellbeing (Malka et al., 2014).

Several important limitations to our conclusions should be addressed. Our measure of political ideology was purely based on self-identification. As suggested by previous research (Zell \& Bernstein, 2014), participants sometimes self-identify as conservative but have leftleaning policy preferences. Measures that assess substantive policy preferences, rather than symbolic identification, may be better suited to capturing ideological asymmetries. An additional limitation concerns the appropriate measurement of dogmatism. Given the heterogeneity of our findings across dogmatism measures, future research involving comparisons of domain-general measures with measures that assess dogmatism across specific domains (e.g., politics, sports, metaphysical beliefs, and so on) and ideologically neutral, performance-based measures of unjustified certainty may be necessary to further clarify our findings. There were also limits to our sample, as only a small number of socialists were present, constraining the utility of our sensitivity analyses separating liberals from leftists. Although these analyses yielded quite promising preliminary results suggesting that liberals and leftists do differ in dogmatism and absolute certainty, we caution against drawing any such conclusions pending replication in a larger and more politically diverse sample.

\section{Conclusion}

Despite decades of theory arguing that absolute certainty and dogmatism are inherent to either right-wingers or extremists, our bottom-line finding is that, while these previous accounts of political dogmatism may possess more than a kernel of truth, differences in thinking styles of conservatives, leftists, extremists, and moderates are ambiguous and context dependent. The rigidity-of-the-right may only apply to social conservatives (see Costello et al., 2021) and far- 
right and far-left ideologies may be in part caused by the same or similar psychological mechanisms (e.g., Zmigrod et al., 2020) while differing dramatically from one another in other ways (e.g., Federico, 2021). In other words, dogmatism is not relegated to a narrow slice of the political spectrum. Nevertheless, moderate liberals appeared to be the least dogmatic political cohort, a finding that is consistent with both the rigidity-of-the-right and ideological extremism hypotheses. 


\section{References}

Akaike, H. (1973). Maximum likelihood identification of Gaussian autoregressive moving average models. Biometrika, 60, 255-265.

Altemeyer, R. A. (1996). The authoritarian specter. Harvard University Press.

Altemeyer, B. (2002). Dogmatic behavior among students: Testing a new measure of dogmatism. The Journal of Social Psychology, 142, 713-721.

Baron, J., \& Jost, J. T. (2019). False equivalence: Are liberals and conservatives in the United States equally biased? Perspectives on Psychological Science, 14, 292-303.

Bowes, S. M., Blanchard, M. C., Costello, T. H., Abramowitz, A. I., \& Lilienfeld, S. O. (2020). Intellectual humility and between-party animus: Implications for affective polarization in two community samples. Journal of Research in Personality, 88, 103992.

Bowes, S. M., Costello, T. H., Lee, C., McElroy-Heltzel, S., Davis, D. E., \& Lilienfeld, S. O. (2021). Stepping Outside the Echo Chamber: Is Intellectual Humility Associated with Less Political Myside Bias? Personality and Social Psychology Bulletin. Advance online publication.

Cassidy, J., Nwanevu, O., \& Slevin, P. (June, 2019). Why Socialism Is Back. The New Yorker. Retrieved from https://www.newyorker.com/news/our-columnists/why-socialism-is-back.

Conway III, L. G., Gornick, L. J., Houck, S. C., Anderson, C., Stockert, J., Sessoms, D., \& McCue, K. (2016). Are conservatives really more simple-minded than liberals? The domain specificity of complex thinking. Political Psychology, 37, 777-798.

Costello, T. H., Bowes, S., Baldwin, M., Lilienfeld, S. O., \& Tasimi, A. (2021, November 6). Are Conservatives More Rigid Than Liberals? A Meta-Analytic Test of the Rigidity-ofthe-Right Hypothesis. https://doi.org/10.31234/osf.io/kq4mn. 
Costello, T.H., Bowes, S.M., Stevens, S.T., Waldman, I.W., Tasimi, A., \& Lilienfeld, S.O. (2021). Clarifying the structure and nature of left-wing authoritarianism. Journal of Personality and Social Psychology.

Costello, T.H., \& Lilienfeld, S.O. (2020). Social and economic political ideology consistently operate as mutual suppressors: Implications for personality, social, and political psychology. Social Psychological and Personality Science. Advance online publication.

Crowson, H. M. (2009). Does the DOG scale measure dogmatism? Another look at construct validity. The Journal of Social Psychology, 149, 365-383.

Davis, D. E., Rice, K., McElroy, S., DeBlaere, C., Choe, E., Van Tongeren, D. R., \& Hook, J. N. (2016). Distinguishing intellectual humility and general humility. The Journal of Positive Psychology, 11, 215-224.

Ditto, P. H., Liu, B. S., Clark, C. J., Wojcik, S. P., Chen, E. E., Grady, R. H., ... \& Zinger, J. F. (2019). At least bias is bipartisan: A meta-analytic comparison of partisan bias in liberals and conservatives. Perspectives on Psychological Science, 14, 273-291.

Duckitt, J. (2009). Authoritarianism and dogmatism. In M. R. Leary \& R. H. Hoyle (Eds.), Handbook of individual differences in social behavior (pp. 298-317). New York, NY: Guilford Press.

Federico, C. M. (2021). When do psychological differences predict political differences?: Engagement and the psychological bases of political polarization. In J.W. van Prooijen (Ed.), The Psychology of Political Polarization (pp. 17-37). Routledge.

Federico, C., \& Malka, A. (2021). Ideology: The Psychological and Social Foundations of Belief Systems. Preprint (https://doi.org/10.31234/osf.io/xhvyj). 
Feldman, S. (2013). Political ideology. In L. Huddy, D. O. Sears, \& J. S. Levy (Eds.), The Oxford handbook of political psychology (pp. 591-626). Oxford University Press.

Godfrey, E. (May, 2020). Thousands of Americans Have Become Socialists Since March. The Atlantic Monthly. Retrieved from https://www.theatlantic.com/politics/archive/2020/05/dsa-growing-duringcoronavirus/611599/.

Harris, E., \& Van Bavel, J. J. (2020). Preregistered replication of "Feeling superior is a bipartisan issue: Extremity (not direction) of political views predicts perceived belief superiority". Psychological Science.

Johnson-Laird, P. N., Legrenzi, P., Girotto, V., Legrenzi, M. S., \& Caverni, J. P. (1999). Naive probability: a mental model theory of extensional reasoning. Psychological Review, 106, $62-88$.

Jost, J. T. (2017). Ideological asymmetries and the essence of political psychology. Political Psychology, 38, 167-208.

Jost, J. T., Glaser, J., Kruglanski, A. W., \& Sulloway, F. J. (2003). Political conservatism as motivated social cognition. Psychological Bulletin, 129, 339-375.

Kahan, D. M. (2013). Ideology, motivated reasoning, and cognitive reflection: An experimental study. Judgment and Decision Making, 8, 407-424.

Kalmoe, N.P. (2020), Uses and abuses of ideology in political psychology. Political Psychology, 41, 771-793.

Kalmoe, N. P., \& Mason, L. (2019, January). Lethal mass partisanship: Prevalence, correlates, and electoral contingencies. In National Capital Area Political Science Association American Politics Meeting. 
Klein, P. (1992). Certainty. In J. Dancy \& E. Sosa (Eds.). A companion to epistemology (61-64). Oxford: Blackwell.

Leary, M. R., Diebels, K. J., Davisson, E. K., Jongman-Sereno, K. P., Isherwood, J. C., Raimi, K. T., ... \& Hoyle, R. H. (2017). Cognitive and interpersonal features of intellectual humility. Personality and Social Psychology Bulletin, 43, 793-813.

Lewis, C. I. (1956). Mind and the world-order: Outline of a theory of knowledge. Courier Corporation.

Levay, K. E., Freese, J., \& Druckman, J. N. (2016). The demographic and political composition of Mechanical Turk samples. Sage Open, 6, 2158244016636433.

Malka, A., Soto, C. J., Inzlicht, M., \& Lelkes, Y. (2014). Do needs for security and certainty predict cultural and economic conservatism? A cross-national analysis. Journal of Personality and Social Psychology, 106, 1031.

Malka, A., \& Soto, C. J. (2015). Rigidity of the economic right? Menu-independent and menudependent influences of psychological dispositions on political attitudes. Current Directions in Psychological Science, 24, 137-142.

McFadden, D. (1974). Conditional logit analysis of qualitative choice behavior. In P. Zarembka (Ed.), Frontiers in econometrics (pp. 104-142). New York: Academic Press.

Popper, K. R. (2020). The open society and its enemies. Princeton University Press.

Raftery, A. E. (1995). Bayesian model selection in social research. Sociological Methodology, 111-163.

Rokeach, M. (1960). The open and closed mind: investigations into the nature of belief systems and personality systems. Basic Books. 
Rollwage, M., Dolan, R. J., \& Fleming, S. M. (2018). Metacognitive failure as a feature of those holding radical beliefs. Current Biology, 28, 4014-4021.

Simonsohn, U. (2018). Two lines: A valid alternative to the invalid testing of U-shaped relationships with quadratic regressions. Advances in Methods and Practices in Psychological Science, 1, 538-555.

Tanesini, A. (2018). Intellectual humility as attitude. Philosophy and phenomenological research, 96, 399-420.

Tetlock, P. E. (1989). Structure and function in political belief systems. In A. R. Pratkanis, S. J. Breckler, \& A. G. Greenwald (Eds.), Attitude structure and function (pp. 129-151). Hillsdale, NJ: Erlbaum.

Toner, K., Leary, M. R., Asher, M. W., \& Jongman-Sereno, K. P. (2013). Feeling superior is a bipartisan issue: Extremity (not direction) of political views predicts perceived belief superiority. Psychological Science, 24, 2454-2462.

Tripp, A. (2018, August 21). Why you should never be certain of your beliefs: a Bayesian perspective. https://www.austintripp.ca/blog/2018/08/21/bayes-no-certain-priors.

Van Hiel, A., Onraet, E., Crowson, H. M., \& Roets, A. (2016). The relationship between rightwing attitudes and cognitive style: A comparison of self-report and behavioural measures of rigidity and intolerance of ambiguity. European Journal of Personality, 30, 523-531.

Van Prooijen, J. W., \& Krouwel, A. P. (2017). Extreme political beliefs predict dogmatic intolerance. Social Psychological and Personality Science, 8, 292-300.

Wagenmakers, E. J. (2007). A practical solution to the pervasive problems of $\mathrm{p}$ values. Psychonomic Bulletin \& Review, 14, 779-804. 
Wilson, A. E., Parker, V. A., \& Feinberg, M. (2020, August 8). Polarization in the contemporary political and media landscape. https://doi.org/10.31219/osf.io/ebp3z.

Zell, E., \& Bernstein, M. J. (2014). You may think you're right... Young adults are more liberal than they realize. Social Psychological and Personality Science, 5, 326-333.

Zmigrod, L., Rentfrow, P. J., \& Robbins, T. W. (2019). Cognitive inflexibility predicts extremist attitudes. Frontiers in Psychology, 10, 989.

Zmigrod, L. (2020). The role of cognitive rigidity in political ideologies: theory, evidence, and future directions. Current Opinion in Behavioral Sciences, 34, 34-39.

Zmigrod, L., Rentfrow, P. J., \& Robbins, T. W. (2020). The partisan mind: Is extreme political partisanship related to cognitive inflexibility? Journal of Experimental Psychology: General, 149, 407-418. 